\title{
Pelatihan Hipnoterapi Untuk Menurunkan Nyeri Dismenorea pada Siswi SMA PGRI I Kota Lubuklinggau
}

\author{
Nadi Aprilyadi, Zuraidah, Indah Dewi Ridawati* \\ ,Poltekkes Kemenkes Palembang, Lubuklinggau, Indonesia \\ *indahdewiridawati@gmail.com
}

\begin{abstract}
ABSTRAK
Di Indonesia prevalensi dismenore pada usia remaja sebesar $64,25 \%$ yang terdiri dari $54,89 \%$ dismenore primer dan 9,36\% dismenore sekunder (Santoso, 2008). Secara farmakologi, penatalaksanaan adalah dengan pemberian obat-obat analgetik seperti golongan obat Nonsteroidal Antiinflammatory Drugs (NSAID) dapat meredakan nyeri. Salah satu pengobatan non farmakologi adalah dengan hipnoterapi merupakan aplikasi hipnosis dalam menyembuhkan masalah mental dan fisik (psikosomatis) seperti halnya nyeri, kecemasan, dan lain-lain. Pengabdian masyarakat ini bertujuan untuk melatih dan memberi penanganan non farmakologi kepada siswi SMA PGRI 1 Kota Lubuklinggau untuk menurunkan nyeri dismenorea Penanganan dismenorea ini diharapkan dapat diterapkan dan dilanjutkan. Pelatihan ini rencananya akan diikuti oleh siswi SMA PGRI I Kota Lubuklinggau berjumlah 38 orang. Hasil yang diperoleh dari kegiatan ini adalah terselenggaranya pelatihan hipnoterapi untuk menurunkan nyeri dismenorea.
\end{abstract}

Kata Kunci: Hipnoterapi, Nyeri Dismenorea, Remaja Putri

\section{PENDAHULUAN}

Dismenorea sering terjadi pada remaja. Studi longitudinal dari Swedia melaporkan dismenorea terjadi pada 90\% wanita yang berusia kurang dari 19 tahun (French, 2005). Dismenorea adalah penyebab utama absen dan terganggu aktifitas lain. Hasil studi menunjukkan hampir $10 \%$ dari wanita dengan dismenorea mengalami tingkat ketidakhadiran 1 sampai 3 hari per bulan dalam bekerja karena dismenorea (Poureslami dan Ashtiani, 2001). Berdasarkan hasil penelitian Mahmudiono pada tahun 2011, angka kejadian dismenore primer pada remaja wanita yang berusia 14 - 19 tahun di Indonesia sekitar 54,89\%. Hasil penelitian Novia pada tahun 2012 menunjukkan 84,4\% remaja usia 16 - 18 tahun di SMA St. Thomas 1 Medan mengalami dismenore. Dengan intensitas nyeri ringan $46,7 \%$, nyeri sedang $30,0 \%$, dan nyeri berat 23,3\%. (Hendarini, 2014).

Dalam pelaksanaan tindakan keperawatan nyeri dapat dikurangi atau dihentikan dengan dua terapi yaitu terapi farmakologis dan non fakmakologis. Terapi farmakologis dilakukan dengan cara pemberian obat analgesik, yang digunakan untuk memblok transmisi stimulus agar terjadinya perubahan persepsi dengan cara mengurangi kortikal terhadap nyeri. Sedangkan terapi non farmakologis dengan cara mengurangi faktor yang 


\section{Journal of Community Engagement in Health}

dapat menambah nyeri misalnya ketidakpercayaan, kesalahpahaman, ketakutan, kelelahan dan kebosanan, memodifikasi stimulus nyeri menggunakan teknik-teknik seperti teknik latihan penglihatan (menonton televisi, berbincang-bincang dengan orang lain, mendengarkan musik), teknik relaksasi (menarik napas dalam), dan stimulasi kulit (menggosok dengan halus pada bagian daerah nyeri, menggosok punggung, menggunakan air hangat dan dingin, memijat dengan air mengalir) (Hidayat, 2013). Tindakan non farmakologi lain untuk mengatasi nyeri, diantaranya yaitu Hipnoterapi, dalam hal ini perawat berperan dalam penanganan secara non farmakologis.

Hipnoterapi adalah salah satu cabang ilmu psikologis yang mempelajari manfaat sugesti untuk mengatasi masalah pikiran, perasaan, dan perilaku. Jika kita mengikuti hipnoterapi, kita akan dibimbing memasuki kondisi trance (relaksasi pikiran) agar pikiran kita siap menerima sugesti yang diberikan oleh hipnoterapis (Muhammad, 2011). Penelitian yang dilakukan kepada 27 orang responden oleh Astari dan Maliya (2010), menunjukkan bahwa sebelum diberi hipnoterapi, tidak terdapat responden yang tidak nyeri $(0 \%)$, responden yang merasa nyeri sedang sebanyak 23 responden $(85,2 \%)$ dan nyeri hebat sebanyak 4 responden $(14,8 \%)$. Setelah diberi hipnoterapi terjadi perubahan tingkat nyeri yang dirasakan responden, yaitu nyeri ringan sebanyak 23 responden $(88,9 \%)$ dan nyeri sedang sebanyak 3 responden $(11,1 \%)$.

Hemi F. dan Jenita S. (2016) menyimpulkan bahwa terdapat pengaruh hipnoterapi terhadap penurunan skala nyeri dismenore. Terdapat dua Mekanisme yang menjelaskan hipnoterapi dapat menurunkan intensitas dismenore primer yaitu dengan pelepasan hormon endorphin sehingga memblok impuls nyeri dan dengan mengubah persepsi nyeri di kortek serebri. Berdasarkan penjajakan di SMA PGRI I Kota Lubuk Linggau para siswi sering mengalami dismenorea pada saat menstruasi yang kadang mengganggu aktivitas siswi. Dalam satu bulan sebanyak 10-16 siswi mengalami keluhan dismenorea saat menstruasi berlangsung. Hasil wawancara kepada tiga siswi baik kelas 1, 2 dan 3 diperoleh keterangan bahwa sudah pernah dilakukan hipnoterapi untuk mengurangi nyeri dismenorea namun belum pernah dilakukan pelatihan hipnoterapi pada siswi SMA PGRI I Kota Lubuklinggau.

\section{METODE}

Metode yang digunakan dalam kegiatan pengabdian kepada masyarakat ini adalah melalui kegiatan pemberian pelatihan hipnoterapi selama 1 hari kepada 38 penderita dismenorea SMA PGRI I Kota Lubuklinggau. Materi yang diberikan dalam pelatihan ini meliputi: 1) Pengantar Dismenorea (definisi, penyebab, tanda dan gejala, pengelolaan dan pencegahan, dan komplikasi), 2) Pengantar Hipnoterapi (definisi, persiapan remaja putri, persiapan alat), 3) melakukan Manfaat hipnoterapi, dan 4) Prosedur Hipnoterapi (Latihan Hipnosis). Metode pelatihan yang diberikan dalam kegiatan pengabdian kepada masyarakat ini adalah berupa pemberian materi disertai dengan metode ceramah dan tanya jawab, latihan hipnoterapi, demonstrasi hipnoterapi dengan memberikan contoh 2 kali setiap tindakan, dan re-demonstrasi hipnoterapi.

Evaluasi dilakukan untuk mengidentifikasi keterampilan remaja putri dalam melakukan hipnoterapi, dimana dalam hal ini digunakan teknik pre-test (evaluasi pertama) dan post-test (evaluasi kedua). Teknik yang dilakukan dalam kegiatan evaluasi adalah dengan melakukan observasi gerakan hipnoterapi yang dilakukan oleh remaja putri sebelum diberikan demonstrasi oleh pemateri (pre-test/ evaluasi pertama). Selanjutnya dilakukan re-demonstrasi hipnoterapi oleh pemateri diikuti oleh remaja putri, dan selanjutnya dilakukan observasi kedua sebagai bentuk evaluasi kedua (post test). 


\section{Journal of Community Engagement in Health}

http://jceh.org

ISSN: 2620-3758 (print); 2620-3766 (online)

https://doi.org/10.30994/jceh.v3i2.67

Vol.3 No.2. Sep 2020. Page.217-224

\section{HASIL DAN PEMBAHASAN \\ Profil}

SMA PGRI I merupakan sekolah menengah atas yang berada di wilayah Kota Lubuklinggau dibawah Yayasan PGRI. Jumlah remaja putri yang pernah mengalami dismenorea sebanyak 38 orang. Kegiatan pengabdian kepada masyarakat ini dilaksanakan pada tanggal 19 Juli 2019 dari jam 08.00 - 13.00 WIB di SMA PGRI I Kota Lubuklinggau. Sasaran dalam kegiatan ini adalah 38 remaja putri dari SMA PGRI I Kota Lubuklinggau tersebut.

\section{Penyampaian materi dan Demonstrasi (Pelaksanaan Kegiatan)}

Kegiatan pelatihan dilakukan dengan pemberian materi dismenorea definisi, (penyebab, tanda dan gejala, pengelolaan dan pencegahan, dan komplikasi) dan hipnoterapi mulai dari pengertian, persiapan, peralatan yang dibutuhkan, manfaat, latihan hipnoterapi, dan gerakan hipnoterapi. Materi ini diberikan sebagai salah satu metode non farmakologis yang dapat diaplikasikan remaja putri yang mengalami dismenorea. Hal ini dapat digunakan sebagai variasi aktivitas dalam penanganan nyeri dismenorea baik di rumah maupun sekolah. Penyuluhan dilakukan dengan memberikan ceramah dengan media powerpoint yang disertai gambar-gambar yang relevan dengan dismenorea dan hipnoterapi.

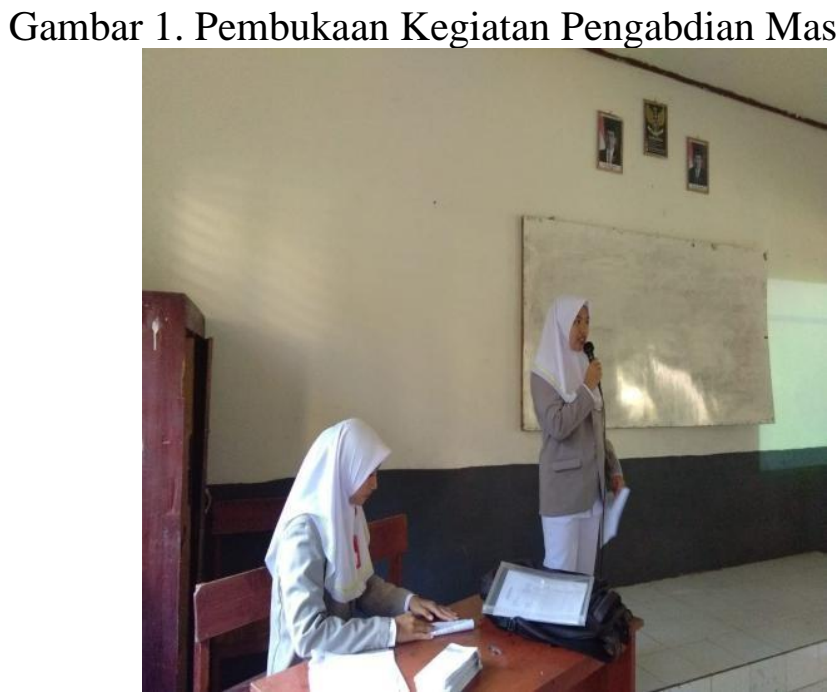

Gambar 2. Sambutan Kepala Sekolah SMA PGRI I Kota Lubuklinggau

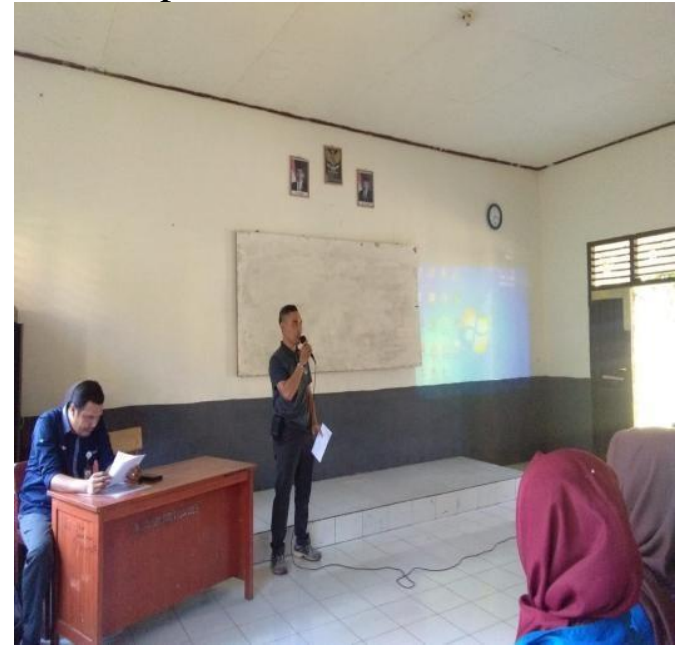




\section{Journal of Community Engagement in Health}

http://jceh.org

ISSN: 2620-3758 (print); 2620-3766 (online)

https://doi.org/10.30994/jceh.v3i2.67

Vol.3 No.2. Sep 2020. Page.217-224

Gambar 3. Sambutan Ketua Kegiatan Pengabdian Masyarakat

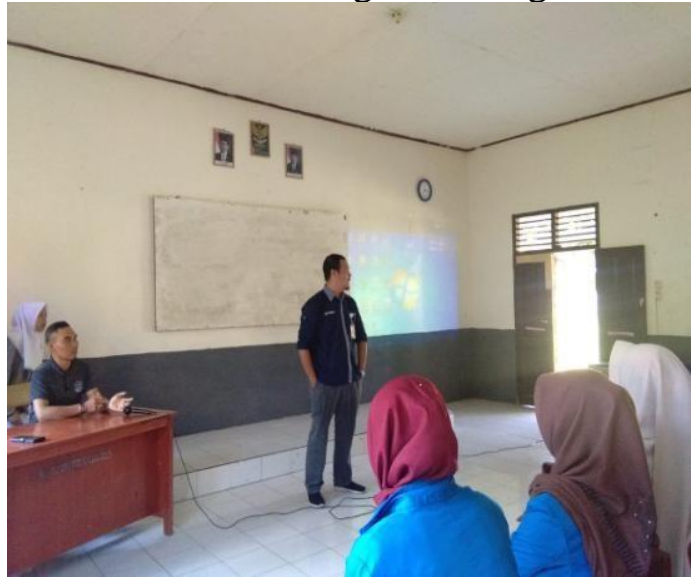

Gambar 4. Pemaparan Materi Dismenorea

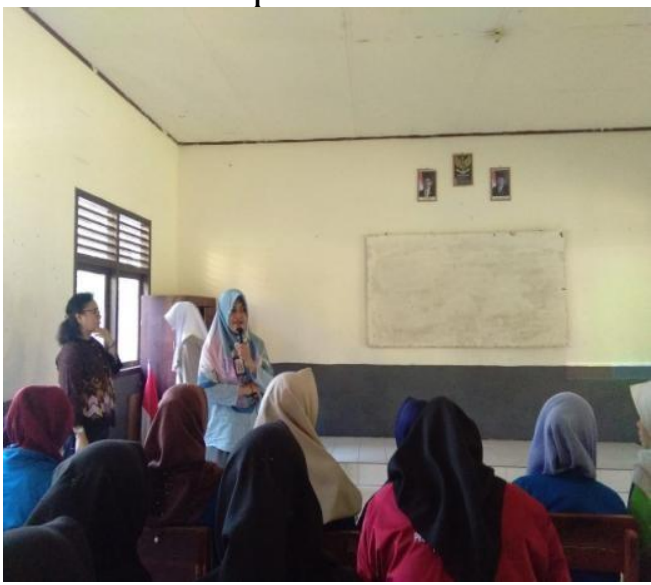

Gambar 5. Pemaparan Materi Hipnoterapi

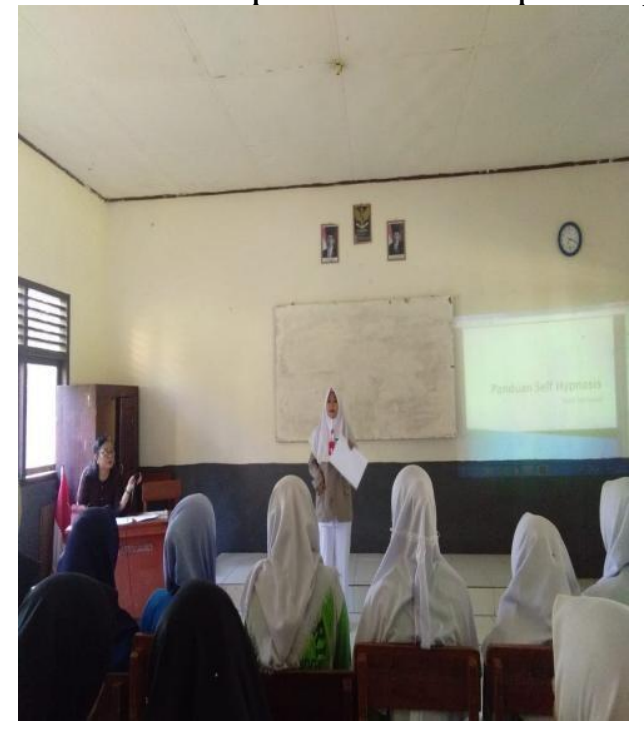




\section{Journal of Community Engagement in Health}

http://jceh.org

ISSN: 2620-3758 (print); 2620-3766 (online)

https://doi.org/10.30994/jceh.v3i2.67

Vol.3 No.2. Sep 2020. Page.217-224

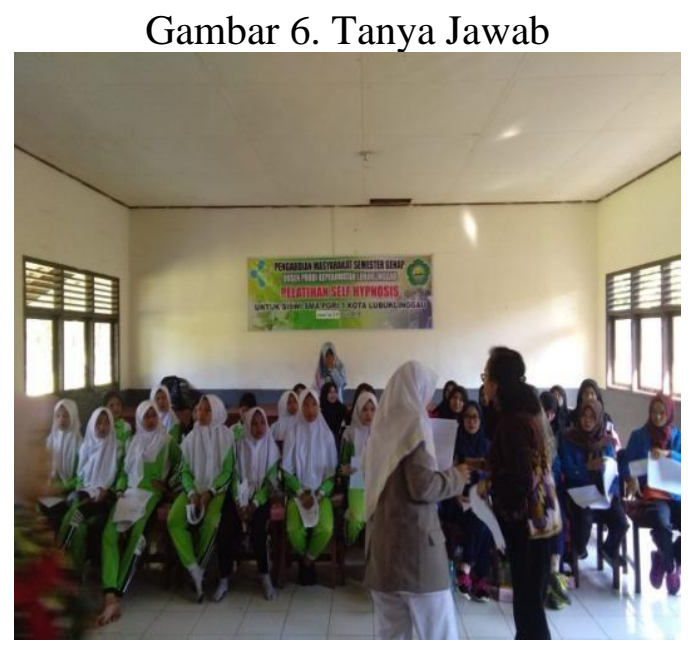

Setelah materi diberikan dan dibuka tanya jawab, dilanjutkan dengan Pre Test (Evaluasi Pertama) sebelum praktik hipnoterapi. Evaluasi ini dengan melihat satu per satu gerakan dari remaja putri serta bertanya ada yang bisa mempraktikan hipnoterapi atau tidak. Hasil evaluasi pertama adalah belum ada satu pun remaja putri di SMA PGRI I Kota Lubuklinggau yang mampu melakukan terapi hipnosis.

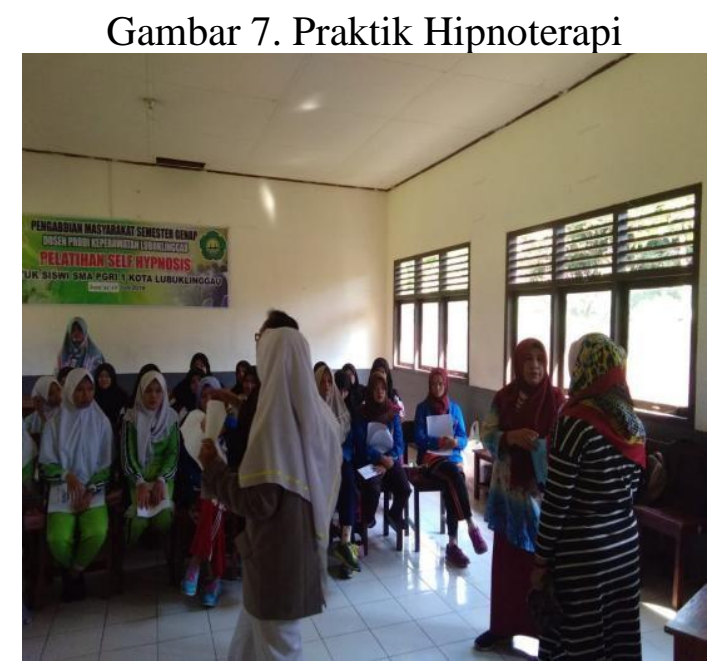

Setelah evaluasi pertama, dilakukan pemberian demonstrasi hipnoterapi pada remaja putri SMA PGRI I Kota Lubuklinggau. Tahapan hipnosis yaitu pra induksi, uji sugestibilitas, induksi, memperdalam dan cek kedalaman trans, pemberian sugesti dan kembali ke kesadaran normal. Latihan hipnoterapi yang diberikan adalah latihan menghipnosis diri sendiri bahwa nyeri dismenorea akan berkurang. Setiap gerakan dicontohkan sebanyak 2 kali. 


\section{Journal of Community Engagement in Health}

http://jceh.org

ISSN: 2620-3758 (print); 2620-3766 (online)

https://doi.org/10.30994/jceh.v3i2.67

Vol.3 No.2. Sep 2020. Page.217-224

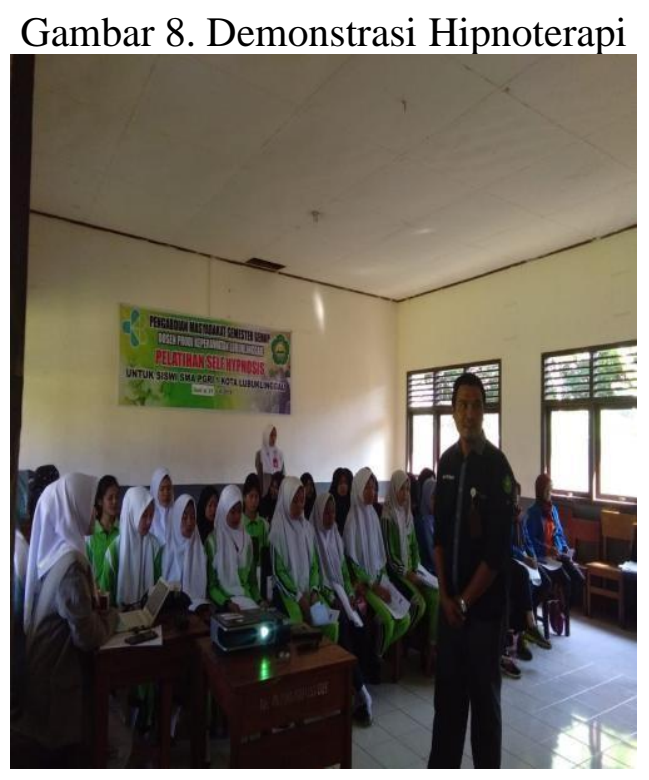

Setelah demonstrasi diberikan, dilakukan evaluasi kedua dengan cara melakukan observasi gerakan hipnosis diri yang dilakukan oleh remaja putri. Observasi dilakukan dengan cara melihat gerakan hipnosis diri. Hasil evaluasi kedua (Post Test) bahwa 30 remaja putri mampu melakukan dengan baik terapi hipnosis namun 8 remaja putri tidak mampu melakukan dengan benar tahapan terapi hipnosis karena kurang konsentrasi dan belum sepenuhnya memahami teknik hipnoterapi. Dengan demikian, kegiatan pelatihan hipnoterapi ini dapat dinyatakan berhasil meskipun harus dilakukan latihan berulang agar lebih menguasai hipnoterapi.

\section{KESIMPULAN}

Siswi SMA PGRI I Kota Lubuklinggau sangat antusias dan semangat dalam memperhatikan materi dan mempraktekkan hipnoterapi. Siswi SMA PGRI I Kota Lubuklinggau akan melakukan hipnosis diri ketika mengalami nyeri dismenorea. Diharapkan setelah mengikuti kegiatan pengabdian masyarakat berupa pelatihan hipnoterapi, kader posyandu lansia dapat menggunakannya sebagai penanganan alternatif nyeri dismenorea baik di sekolah maupun di rumah.

\section{UCAPAN TERIMAKASIH}

Ucapan terimakasih disampaikan kepada Poltekkes Kemenkes Palembang, karena pelaksanaan kegiatan pengabdian kepada masyarakat ini dapat terselenggara atas dukungan dana dari Poltekkes Kemenkes Palembang. Selain itu, ucapan terimakasih juga disampaikan kepada siswi, mahasiswi yang sedang KKN, dan guru SMA PGRI I Kota Lubuklinggau yang telah bersedia bekerjasama dan membantu teknis pelaksanaan kegiatan ini dengan baik. Tidak lupa disampaikan terimakasih kepada Kepala Sekolah yang turut hadir dan memberikan sambutan dalam kegiatan pelatihan ini.

\section{REFERENSI}

Arif, Antonius. 2011. The Handbook Of Hypnoterapy Scripts \& Strategies. Jakarta :

Kompas Gramedia 


\section{Journal of Community Engagement in Health}

http://jceh.org

ISSN: 2620-3758 (print); 2620-3766 (online)

https://doi.org/10.30994/jceh.v3i2.67

Vol.3 No.2. Sep 2020. Page.217-224

Budi, Prabowo Prasetyo \& Rizali, Erwin. 2010. Cara Cepat Menguasai Hypno Healing Hipnosis untuk Penyembuhan. Yogyakarta : Grafina Mediacipta Cv

Andarmoyo,S. 2013. Konsep \& Proses Keperawatan Nyeri. Jogjakarta : Ar-Ruzz

Asmadi. 2008. Teknik Prosedural Keperawatan : Konsep dan Aplikasi Kebutuhan Dasar Klien. Jakarta : Salemba Medika

Dobson, James.2006. Preparing for adolense.California : Vision House

Efendi, Ferrry \& Makhfudli.2009. Keperawatan Kesehatan Komunitas : Teori dan Praktik dalam Keperawatan. Jakarta : Salemba Medika

Helmi F dan Jenita S (2016). Pengaruh Hipnoterapi terhadap Disemnore Primer pada Siswi Sekolah Menengah Pertama. JKA.2016; 3(1): 69-75

Hidayat, Aziz Alimul. 2013. Pengantar Kebutuhan Dasar Manusia-Aplikasi Konsep dan Proses Keperawatan. Jakarta : Salemba Medika

Hutabarat, Melati \& Permana,Rahma \& Masud, Mahzhuranni. 2010. 24 Kreasi Unik Kamar Remaja. Jakarta : Penebar Swadaya

Judha, M \& Sudiarti. 2012. Teori Pengukuran Nyeri dan Nyeri Persalinan. Yogyakarta : Nuha Medika

Kumalasari, Intan \& Andhyantoro, Iwan. 2014. Kesehatan Reproduksi untuk Mahasiswa Kebidanan dan Keperawatan. Jakarta : Salemba Medika

Lukman, Ningsih Nurma. 2012. Asuhan Keperawatan Pada Klien Dengan Gangguan Sistem Muskuloskeletal. Jakarta : Salemba Medika

Masjoer Arif dkk. 2001. Kapita Selekta Kedokteran Edisi Ketiga Jilid 1. Jakarta : Media Aesculapius

Muhammad As'adi. 2011. Melakukan Hinoterapi agar Daya Ingat Anda Sekuat Cakram. Yogyakarta : DIVA Press

Muttaqin Arif. 2008. Buku Ajar Asuhan Keperawatan Klien dengan Gangguan sistem persarafan. Jakarta : Salemba Medika

Monks FJ, Knoers, Haditomo. 2002. Psikologi Perkembangan : Pengantar dalam Berbagai Bagiannya. Yogyakarta : Gadjah Mada University Press

Proverawati Atikah. 2009. Menstruasi Pertama Penuh Makna. Yogyakarta : Nuha Medika

Saryono, Widianti Anggriyana Tri. 2011. Cacatan Kuliah Kebutuhan Dasar Manusia $(K D M)$. Jogjakarta : Nuha Medika 


\section{Journal of Community Engagement in Health}

http://jceh.org

ISSN: 2620-3758 (print); 2620-3766 (online)

https://doi.org/10.30994/jceh.v3i2.67

Vol.3 No.2. Sep 2020. Page.217-224

Setiyohadi Bambang dkk. 2006. Ilmu Penyakit dalam. Jakarta : FKUI

Smeltzer, Suzanne C. 2001. Buku Ajar Keperawtan Medikal Bedah. Brunner \& Suddarth. Edisi 8. Jakarta : EGC

Suwandi Awie.2010.Turbo Hipnotis : Rahasia Belajar Instan \& Aplikasi Hipnotis Praktis. Jakarta : PT Gramedia Pustaka Utama

Tambayong Jan. 2000. Patofisiologi untuk keperawatan. Jakaarta : EGC

Tarwoto dkk. 2010. Kesehatan Remaja : Problem dan Solusinya. Jakarta : Salemba Medika

Toy, Harun; etc. 2016. Autistic traits in women with primary dysmenorrhea: a casecontrol study. Neuropsychiatric Disease and Treatment 2016:12 2319-2325

Wong Willy, Andri Hakim. 2009. Dahsyatnya Hipnosis. Jakarta : Visimedia Yulaikhah lily.2008. Kehamilan : Seri Asuh Kebidanan. Jakarta: EGC 